\title{
ORchestra: an online reference database of OR/MS literature in health care
}

\author{
Peter J. H. Hulshof • Richard J. Boucherie • J. Theresia van Essen • \\ Erwin W. Hans • Johann L. Hurink • Nikky Kortbeek • Nelly Litvak • \\ Peter T. Vanberkel • Egbert van der Veen • Bart Veltman • \\ Ingrid M. H. Vliegen • Maartje E. Zonderland
}

Received: 1 June 2011 / Accepted: 5 June 2011 / Published online: 7 July 2011

(C) The Author(s) 2011. This article is published with open access at Springerlink.com

\begin{abstract}
We introduce the categorized reference database ORchestra, which is available online at http:// www.utwente.nl/choir/orchestra/.
\end{abstract}

Keywords Health care services • Operations Research and Management Science (OR/MS) •

Reference database $\cdot$ Bibliography

With this note, we introduce a reference database for Operations Research and Management Science (OR/ MS) literature in health care, named 'ORchestra' [6]. ORchestra is available online and can be searched by both medical and OR/MS keywords.

P. J. H. Hulshof $(\bowtie) \cdot$ N. Kortbeek $(\bowtie)$

University of Twente, P.O. Box 217, 7500 AE Enschede,

The Netherlands

e-mail: p.j.h.hulshof@utwente.nl

e-mail: n.kortbeek@utwente.nl

e-mail: orchestra@choir.utwente.nl

URL: http://www.utwente.nl/choir/orchestra/

P. J. H. Hulshof · R. J. Boucherie - J. T. van Essen ·

E. W. Hans · J. L. Hurink · N. Kortbeek · N. Litvak .

P. T. Vanberkel · E. van der Veen - B. Veltman .

I. M. H. Vliegen - M. E. Zonderland

Center for Healthcare Operations Improvement

and Research (CHOIR), University of Twente,

Enschede, The Netherlands

e-mail: orchestra@choir.utwente.nl
OR/MS is an interdisciplinary branch of applied mathematics, engineering and sciences that uses various scientific research-based principles, strategies, and analytical methods including mathematical modeling, statistics and algorithms to improve an organization's ability to enact rational and meaningful management decisions [4]. OR/MS has been applied widely to support management decisions in manufacturing. Since the 1950s, OR/MS also yields significant contributions in the health care sector.

Due to the interdisciplinary nature of OR/MS applied to health care, there is an extensive base of literature published across various academic fields. Tailored reference databases prove to be valuable in retrieving references from this broad availability. For example, Dexter provides a comprehensive bibliography on operating room management articles [1]. 'ORCHID' is a reference library, which was maintained until 2007 by the University of Toronto and Monash University [7] and remains available at our website [6].

Members of the Center for Healthcare Operations Improvement and Research (CHOIR) of the University of Twente, the Netherlands, develop, update and maintain ORchestra. References in ORchestra are in the first place categorized by medical topics and $\mathrm{OR} / \mathrm{MS}$ technique. The medical topics are derived from Medical Subject Headings (MeSH) [5]. In addition, references are classified in the hierarchical levels of strategic, tactical, offline operational and online operational planning [2].

In [3] a taxonomy is proposed that incorporates the aforementioned hierarchical planning levels to support and integrate decision making in resource capacity planning and control in health care. This taxonomy is used to identify, break down and classify these de- 
cisions. For each identified decision in six different care services, relevant OR/MS literature is reviewed. An other CHOIR survey reviews OR/MS literature to determine the extent to which model scopes encompass multiple hospital departments [8]. All articles referred in $[3,8]$ are included in ORchestra.

Summarizing, ORchestra provides a reference resource for health care managers, clinical staff and OR/ MS researchers in health care. It can be a valuable starting point for other literature reviews within the scope of OR/MS in health care. We invite everyone to contribute to ORchestra by submitting references through our website [6]. Members of CHOIR then verify and add these contributions to ORchestra. We welcome any contributions, suggestions or remarks that help us to further improve ORchestra.

Acknowledgements This research is supported by the Dutch Technology Foundation STW, applied science division of NWO and the Technology Program of the Ministry of Economic Affairs.

Open Access This article is distributed under the terms of the Creative Commons Attribution Noncommercial License which permits any noncommercial use, distribution, and reproduction in any medium, provided the original author(s) and source are credited.

\section{References}

1. Dexter F (2011) Bibliography of operating room management articles. http://www.franklindexter.com/. Retrieved 13 May 2011

2. Hans EW, Van Houdenhoven M, Hulshof PJH (2011) A framework for health care planning and control. Memorandum 1938, Department of Applied Mathematics, University of Twente, Enschede. ISSN 1874-4850, available at http://www. math.utwente.nl/publications

3. Hulshof PJH, Kortbeek N, Boucherie RJ, Hans EW (2011) Taxonomic classification of planning decisions in health care: a review of the state of the art in OR/MS. Memorandum 1944, Department of Applied Mathematics, University of Twente, Enschede. ISSN 1874-4850, available at http://www. math.utwente.nl/publications

4. INFORMS (2011) http://www.informs.org/. Retrieved 13 May 2011

5. Medical Subject Headings (MeSH) (2011) http://www.nlm.nih. gov/mesh/. Retrieved 13 May 2011

6. ORchestra (2011) ORchestra, developed and maintained by the Center for Healthcare Operations and Improvement Research (CHOIR) at the University of Twente. http://www. utwente.nl/choir/orchestra/. Retrieved 13 May 2011

7. ORCHID (2011) ORCHID, developed and maintained by the Centre for Research in Healthcare Engineering (CRHE) at the University of Toronto and the School of Business Systems of Monash University until 2007, available at http:// www.utwente.nl/choir/orchestra/. Retrieved 13 May 2011

8. Vanberkel PT, Boucherie RJ, Hans EW, Hurink JL, Litvak N (2011) A survey of health care models that encompass multiple departments. International Journal of Health Management and Information 1(1):37-69 